\title{
Four-Point Optimal Sixteenth-Order Iterative Method for Solving Nonlinear Equations
}

\author{
Malik Zaka Ullah, ${ }^{1}$ A. S. Al-Fhaid, ${ }^{1}$ and Fayyaz Ahmad ${ }^{2}$ \\ ${ }^{1}$ Department of Mathematics, King Abdulaziz University, Jeddah 21589, Saudi Arabia \\ ${ }^{2}$ Department de Fisica i Enginyeria Nuclear, Universitat Politecnica de Catalunya, 08036 Barcelona, Spain
}

Correspondence should be addressed to Malik Zaka Ullah; mzhussain@kau.edu.sa

Received 10 April 2013; Accepted 27 July 2013

Academic Editor: Saeid Abbasbandy

Copyright (C) 2013 Malik Zaka Ullah et al. This is an open access article distributed under the Creative Commons Attribution License, which permits unrestricted use, distribution, and reproduction in any medium, provided the original work is properly cited.

We present an iterative method for solving nonlinear equations. The proposed iterative method has optimal order of convergence sixteen in the sense of Kung-Traub conjecture (Kung and Traub, 1974); it means that the iterative scheme uses five functional evaluations to achieve $16\left(=2^{5-1}\right)$ order of convergence. The proposed iterative method utilizes one derivative and four function evaluations. Numerical experiments are made to demonstrate the convergence and validation of the iterative method.

\section{Introduction}

According to Kung and Traub conjecture, a multipoint iterative method without memory could achieve optimal convergence order $2^{n-1}$ by performing $n$ evaluations of function or its derivatives [1]. In order to construct an optimal sixteenthorder convergent iterative method for solving nonlinear equations, we require four and eight optimal-order iterative schemes. Many authors have been developed the optimal eighth-order iterative methods, namely, Bi et al. [2], Bi et al. [3], Geum and Kim [4], Liu and Wang [5], Wang and Liu [6], and Soleymani et al. [7-9]. Some recent applications of nonlinear equation solvers in matrix inversion for regular or rectangular matrices have been introduced in [10-12].

For the proposed iterative method, we developed new optimal fourth- and eighth-orders iterative methods to construct optimal sixteenth-order iterative scheme. On the other hand, it is known that rational weight functions give a better convergence radius. By keeping this fact in mind, we introduced rational terms in weight functions to achieve optimal sixteenth order.

For the sake of completeness, we list some existing optimal sixteenth-order convergent methods. Babajee and Thukral [13] suggested 4-point sixteenth-order king family of iterative methods for solving nonlinear equations (BT):

$$
\begin{gathered}
y_{n}=x_{n}-\frac{f\left(x_{n}\right)}{f^{\prime}\left(x_{n}\right)}, \\
z_{n}=y_{n}-\frac{1+\beta t_{1}}{1+(\beta-2) t_{1}} \frac{f\left(y_{n}\right)}{f^{\prime}\left(x_{n}\right)}, \\
w_{n}=z_{n}-\left(\theta_{0}+\theta_{1}+\theta_{2}+\theta_{3}\right) \frac{f\left(y_{n}\right)}{f^{\prime}\left(x_{n}\right)}, \\
x_{n+1}=w_{n}-\left(\theta_{0}+\theta_{1}+\theta_{2}+\theta_{3}+\theta_{4}+\theta_{5}+\theta_{6}+\theta_{7}\right) \frac{f\left(w_{n}\right)}{f^{\prime}\left(x_{n}\right)},
\end{gathered}
$$

where

$$
\begin{gathered}
t_{1}=\frac{f\left(y_{n}\right)}{f\left(x_{n}\right)}, \quad t_{2}=\frac{f\left(z_{n}\right)}{f\left(x_{n}\right)}, \quad t_{3}=\frac{f\left(z_{n}\right)}{f\left(y_{n}\right)}, \\
t_{4}=\frac{f\left(w_{n}\right)}{f\left(x_{n}\right)}, \quad t_{5}=\frac{f\left(w_{n}\right)}{f\left(z_{n}\right)}, \quad t_{6}=\frac{f\left(w_{n}\right)}{f\left(y_{n}\right)}, \\
\theta_{0}=1, \quad \theta_{1}=\frac{1+\beta t_{1}+3 / 2 \beta t_{1}^{2}}{1+(\beta-2) t_{1}+(3 / 2 \beta-1) t_{1}^{2}}-1,
\end{gathered}
$$




$$
\begin{gathered}
\theta_{2}=t_{3}, \quad \theta_{3}=4 t_{2}, \quad \theta_{4}=t_{5}+t_{1} t_{2}, \\
\theta_{5}=2 t_{1} t_{5}+4(1-\beta) t_{1}^{3} t_{3}+2 t_{2} t_{3}, \\
\theta_{6}=2 t_{6}+\left(7 \beta^{2}-\frac{47}{2} \beta+14\right) t_{3} t_{1}^{4} \\
+(2 \beta-3) t_{2}^{2}+(5-2 \beta) t_{5} t_{1}^{2}-t_{3}^{3}, \\
\theta_{7}=8 t_{4}+\left(-12 \beta+2 \beta^{2}+12\right) t_{5} t_{1}^{3} \\
-4 t_{3}^{3} t_{1}+\left(-2 \beta^{2}+12 \beta-22\right) t_{3}^{2} t_{1}^{3} \\
+\left(-10 \beta^{3}+\frac{127}{2} \beta^{2}-105 \beta+46\right) t_{2} t_{1}^{4} .
\end{gathered}
$$

In 2011, Geum and Kim [14] proposed a family of optimal sixteenth-order multipoint methods (GK2):

$$
\begin{gathered}
y_{n}=x_{n}-\frac{f\left(x_{n}\right)}{f^{\prime}\left(x_{n}\right)}, \\
z_{n}=-K_{f}\left(u_{n}\right) \frac{f\left(y_{n}\right)}{f^{\prime}\left(x_{n}\right)}, \\
s_{n}=z_{n}-H_{f}\left(u_{n}, v_{n}, w_{n}\right) \frac{f\left(z_{n}\right)}{f^{\prime}\left(x_{n}\right)}, \\
x_{n+1}=s_{n}-W_{f}\left(u_{n}, v_{n}, w_{n}, t_{n}\right) \frac{f\left(s_{n}\right)}{f^{\prime}\left(x_{n}\right)},
\end{gathered}
$$

where

$$
\begin{gathered}
u_{n}=\frac{f\left(y_{n}\right)}{f\left(x_{n}\right)}, \quad v_{n}=\frac{f\left(z_{n}\right)}{f\left(y_{n}\right)}, \\
w_{n}=\frac{f\left(z_{n}\right)}{f\left(x_{n}\right)}, \quad t_{n}=\frac{f\left(s_{n}\right)}{f\left(z_{n}\right)}, \\
K_{f}\left(u_{n}\right)=\frac{1+\beta u_{n}+(-9+5 / 2 \beta) u_{n}^{2}}{1+(\beta-2) u_{n}+(-4+\beta / 2) u_{n}^{2}}, \\
H_{f}=\frac{1+2 u_{n}+(2+\sigma) w_{n}}{1-v_{n}+\sigma w_{n}}, \\
W_{f}=\frac{1+2 u_{n}}{1-v_{n}-2 w_{n}-t_{n}}+G\left(u_{n}, v_{n}, w_{n}\right),
\end{gathered}
$$

one of the choices for $G\left(u_{n}, v_{n}, w_{n}\right)$ along with $\beta=24 / 11$ and $\sigma=-2$ :

$$
\begin{aligned}
G\left(u_{n}, v_{n}, w_{n}\right)= & -6 u_{n}^{3} v_{n}-\frac{244}{11} u_{n}^{4} w_{n} \\
& +6 w_{n}^{2}+u_{n}\left(2 v_{n}^{2}+4 v_{n}^{3}+w_{n}-2 w_{n}^{2}\right)
\end{aligned}
$$

In the same year, Geum and Kim [15] presented a biparametric family of optimally convergent sixteenth-order multipoint methods (GK1):

$$
\begin{gathered}
y_{n}=x_{n}-\frac{f\left(x_{n}\right)}{f^{\prime}\left(x_{n}\right)}, \\
z_{n}=-K_{f}\left(u_{n}\right) \frac{f\left(y_{n}\right)}{f^{\prime}\left(x_{n}\right)}, \\
s_{n}=z_{n}-H_{f}\left(u_{n}, v_{n}, w_{n}\right) \frac{f\left(z_{n}\right)}{f^{\prime}\left(x_{n}\right)}, \\
x_{n+1}=s_{n}-W_{f}\left(u_{n}, v_{n}, w_{n}, t_{n}\right) \frac{f\left(s_{n}\right)}{f^{\prime}\left(x_{n}\right)},
\end{gathered}
$$

where

$$
\begin{gathered}
u_{n}=\frac{f\left(y_{n}\right)}{f\left(x_{n}\right)}, \quad v_{n}=\frac{f\left(z_{n}\right)}{f\left(y_{n}\right)}, \\
w_{n}=\frac{f\left(z_{n}\right)}{f\left(x_{n}\right)}, \quad t_{n}=\frac{f\left(s_{n}\right)}{f\left(z_{n}\right)}, \\
K_{f}\left(u_{n}\right)=\frac{1+\beta u_{n}+(-9+5 / 2 \beta) u_{n}^{2}}{1+(\beta-2) u_{n}+(-4+\beta / 2) u_{n}^{2}}, \\
H_{f}=\frac{1+2 u_{n}+(2+\sigma) w_{n}}{1-v_{n}+\sigma w_{n}}, \\
W_{f}=\frac{1+2 u_{n}+(2+\sigma) v_{n} w_{n}}{1-v_{n}-2 w_{n}-t_{n}+2(1+\sigma) v_{n} w_{n}} \\
+G\left(u_{n}, w_{n}\right),
\end{gathered}
$$

one of the choices for $G\left(u_{n}, w_{n}\right)$ along with $\beta=2$ and $\sigma=-2$ :

$$
\begin{gathered}
G\left(u_{n}, w_{n}\right)=-\frac{1}{2}\left[u _ { n } w _ { n } \left(6+12 u_{n}+(24-11 \beta) u_{n}^{2}\right.\right. \\
\left.\left.+u_{n}^{3} \phi_{1}+4 \sigma\right)\right]+\phi_{2} w_{n}^{2} \\
\phi_{1}=\left(11 \beta^{2}-66 \beta+136\right) \\
\phi_{2}=\left(2 u_{n}\left(\sigma^{2}-2 \sigma-9\right)-4 \sigma-6\right) .
\end{gathered}
$$

\section{A New Method and Convergence Analysis}

The proposed sixteenth-order iterative method is described as follows (MA):

$$
\begin{gathered}
y_{n}=x_{n}-\frac{f\left(x_{n}\right)}{f^{\prime}\left(x_{n}\right)}, \\
z_{n}=y_{n}-\frac{1+2 t_{1}-t_{1}^{2}}{1-6 t_{1}^{2}} \frac{f\left(y_{n}\right)}{f^{\prime}\left(x_{n}\right)}, \\
w_{n}=z_{n}-\frac{1-t_{1}+t_{3}}{1-3 t_{1}+2 t_{3}-t_{2}} \frac{f\left(z_{n}\right)}{f^{\prime}\left(x_{n}\right)},
\end{gathered}
$$


TABLE 1: Set of six test nonlinear functions.

\begin{tabular}{lc}
\hline Functions & Roots \\
\hline$f_{1}(x)=e^{x} \sin (x)+\log \left(1+x^{2}\right)$ & $\alpha=0$ \\
$f_{2}(x)=(x-2)\left(x^{10}+x+1\right) e^{-x-1}$ & $\alpha=2$ \\
$f_{3}(x)=\sin (x)^{2}-x^{2}+1$ & $\alpha=1.40449 \ldots$ \\
$f_{4}(x)=e^{-x}-\cos (x)$ & $\alpha=0$ \\
$f_{5}(x)=x^{3}+\log (x)$ & $\alpha=0.70470949 \ldots$ \\
\hline
\end{tabular}

TABLE 2: Numerical comparison of absolute error $\left|x_{n}-\alpha\right|$, number of iterations $=3$.

\begin{tabular}{|c|c|c|c|c|c|}
\hline$\left(f_{n}(x), x_{0}\right)$ & Iter/COC & MA & BT & GK1 & GK2 \\
\hline \multirow{4}{*}{$f_{1}, 1.0$} & 1 & 0.00268 & 0.00183 & 0.0111 & 0.00230 \\
\hline & 2 & $2.03 e-37$ & $1.71 e-37$ & $6.35 e-24$ & $5.61 e-34$ \\
\hline & 3 & $2.47 e-583$ & $3.53 e-582$ & $1.37 e-363$ & $1.03 e-523$ \\
\hline & $\mathrm{COC}$ & 16 & 16 & 16 & 16 \\
\hline \multirow{4}{*}{$f_{2}, 2.5$} & 1 & 0.04086 & 0.0639 & 0.0296 & 0.00866 \\
\hline & 2 & $6.16 e-9$ & 650.0 & $5.35 e-14$ & $2.53 e-21$ \\
\hline & 3 & $1.50 e-121$ & Divergent & $4.79 e-201$ & $1.89 e-317$ \\
\hline & $\mathrm{COC}$ & 16.5 & - & 15.9 & 16.0 \\
\hline \multirow{4}{*}{$f_{3}, 2.5$} & 1 & 0.0000326 & 0.0000303 & 0.000497 & 0.0000677 \\
\hline & 2 & $4.87 e-73$ & $1.70 e-72$ & $1.56 e-51$ & $1.14 e-64$ \\
\hline & 3 & $3.11 \mathrm{e}-1158$ & $1.63 e-1148$ & $1.42 e-811$ & $4.52 e-1021$ \\
\hline & $\mathrm{COC}$ & 16 & 16 & 16 & 16 \\
\hline \multirow{4}{*}{$f_{4}, 1 / 6$} & 1 & $2.79 e-7$ & 0.0000864 & $1.28 e-7$ & 0.000167 \\
\hline & 2 & $1.00 e-109$ & $1.18 e-63$ & $2.28 e-107$ & $9.28 e-57$ \\
\hline & 3 & $2.80 e-1851$ & $1.72 e-1005$ & $2.24 e-1703$ & $7.82 e-893$ \\
\hline & $\mathrm{COC}$ & 17 & 16 & 16 & 16 \\
\hline \multirow{4}{*}{$f_{5}, 3.0$} & 1 & 0.0486 & 0.135 & 0.0949 & 0.0133 \\
\hline & 2 & $1.95 e-22$ & $1.81 e-17$ & $1.78 e-19$ & $1.11 e-35$ \\
\hline & 3 & $8.46 e-349$ & $1.79 e-271$ & $6.86 e-302$ & $2.61 e-563$ \\
\hline & $\mathrm{COC}$ & 16.0 & 16.0 & 15.9 & 16.0 \\
\hline
\end{tabular}

$$
\begin{aligned}
x_{n+1}=w_{n}-( & q_{1}+q_{2}+q_{3}+q_{4} \\
& \left.+q_{5}+q_{6}+q_{7}\right) \frac{f\left(w_{n}\right)}{f^{\prime}\left(x_{n}\right)},
\end{aligned}
$$

where

$$
\begin{gathered}
t_{1}=\frac{f\left(y_{n}\right)}{f\left(x_{n}\right)}, \quad t_{2}=\frac{f\left(z_{n}\right)}{f\left(y_{n}\right)}, \\
t_{3}=\frac{f\left(z_{n}\right)}{f\left(x_{n}\right)}, \quad t_{4}=\frac{f\left(w_{n}\right)}{f\left(x_{n}\right)}, \\
t_{5}=\frac{f\left(w_{n}\right)}{f\left(y_{n}\right)}, \quad t_{6}=\frac{f\left(w_{n}\right)}{f\left(z_{n}\right)}, \\
q_{1}=\frac{1}{1-2\left(t_{1}+t_{1}^{2}+t_{1}^{3}+t_{1}^{4}+t_{1}^{5}+t_{1}^{6}+t_{1}^{7}\right)}, \\
q_{2}=\frac{4 t_{3}}{1-31 / 4 t_{3}}, \quad q_{3}=\frac{t_{2}}{1-t_{2}-20 t_{2}^{3}}, \\
q_{4}=\frac{8 t_{4}}{1-t_{4}}+\frac{2 t_{5}}{1-t_{5}}+\frac{t_{6}}{1-t_{6}},
\end{gathered}
$$

$$
\begin{gathered}
q_{5}=\frac{15 t_{1} t_{3}}{1-131 / 15 t_{3}}, \quad q_{6}=\frac{54 t_{1}^{2} t_{3}}{1-t_{1}^{2} t_{3}}, \\
q_{7}=7 t_{2} t_{3}+2 t_{1} t_{6}+6 t_{6} t_{1}^{2}+188 t_{3} t_{1}^{3} \\
+18 t_{6} t_{1}^{3}+9 t_{2}^{2} t_{3}+648 t_{1}^{4} t_{3} .
\end{gathered}
$$

Theorem 1. Let $f: D \subseteq \mathbb{R} \rightarrow \mathbb{R}$ be a sufficiently differentiable function, and $\alpha \in D$ is a simple root of $f(x)=0$, for an open interval D. If $x_{0}$ is chosen sufficiently close to $\alpha$, then the iterative scheme (9) converges to $\alpha$ and shows an order of convergence at least equal to sixteen.

Proof. Let error at step $n$ be denoted by $e_{n}=x_{n}-\alpha$ and $c_{1}=f^{\prime}(\alpha)$ and $c_{k}=(1 / k !)\left(f^{(k)}(\alpha) / f^{\prime}(\alpha)\right), k=2,3, \ldots$ We provided Maple based computer assisted proof in Algorithm 1 and got the following error equation:

$$
\begin{aligned}
e_{n+1}=-c_{4} c_{3} c_{2}^{2}\left(c_{5} c_{3} c_{2}^{2}+2 c_{4} c_{2} c_{3}^{2}\right. & \\
& -20 c_{3}^{4}-51 c_{3}^{3} c_{2}^{2}+522 c_{3}^{2} c_{2}^{4}
\end{aligned}
$$




$$
\begin{aligned}
& -2199 c_{3} c_{2}^{6}+2 c_{2}^{8}-30 c_{4} c_{3} c_{2}^{3} \\
& \left.+54 c_{4} c_{2}^{5}\right) e_{n}^{16}+O\left(e_{n}^{17}\right) .
\end{aligned}
$$

\section{Numerical Results}

If the convergence order $\eta$ is defined as

$$
\lim _{x \rightarrow \infty} \frac{\left|e_{n+1}\right|}{\left|e_{n}\right|^{\eta}}=c \neq 0,
$$

then the following expression approximates the computational order of convergence (COC) [16] as follows:

$$
\rho \approx \frac{\ln \left|\left(x_{n+1}-\alpha\right) /\left(x_{n}-\alpha\right)\right|}{\ln \left|\left(x_{n}-\alpha\right) /\left(x_{n-1}-\alpha\right)\right|}
$$

where $\alpha$ is the root of nonlinear equation. A set of five nonlinear equations are used for numerical computations in Table 1. Three iterations are performed to calculate the absolute error $\left(\left|x_{n}-\alpha\right|\right)$ and computational order of convergence. Table 2 shows absolute error and computational order of convergence, respectively.

\section{Conclusion}

An optimal sixteenth-order iterative scheme has been developed for solving nonlinear equations. A Maple program is provided to calculate error equation, which actually shows the optimal order of convergence in the sense of KungTraub conjecture. The computational order of convergence also verifies our claimed order of convergence. The proposed scheme uses four functions and one derivative evaluation per full cycle, which gives 1.741 as the efficiency index. We also have shown the validity of our proposed iterative scheme by comparing it with other existing optimal sixteenth-order iterative methods. The numerical results show that the performance of iterative scheme is competitive as compared to other methods.

\section{Acknowledgments}

The first and the second authors were funded by the Deanship of Scientific Research (DSR), King Abdulaziz University, Jeddah. They, therefore, acknowledge with thanks DSR technical and financial support while the third author is supported for this research under the Spanish MEC Grants AYA2010-15685.

\section{References}

[1] H. T. Kung and J. F. Traub, "Optimal order of one-point and multipoint iteration," Journal of the Association for Computing Machinery, vol. 21, pp. 643-651, 1974.

[2] W. Bi, H. Ren, and Q. Wu, "Three-step iterative methods with eighth-order convergence for solving nonlinear equations," Journal of Computational and Applied Mathematics, vol. 225, no. 1, pp. 105-112, 2009.
[3] W. Bi, Q. Wu, and H. Ren, "A new family of eighth-order iterative methods for solving nonlinear equations," Applied Mathematics and Computation, vol. 214, no. 1, pp. 236-245, 2009.

[4] Y. H. Geum and Y. I. Kim, "A multi-parameter family of threestep eighth-order iterative methods locating a simple root," Applied Mathematics and Computation, vol. 215, no. 9, pp. 33753382, 2010.

[5] L. Liu and X. Wang, "Eighth-order methods with high efficiency index for solving nonlinear equations," Applied Mathematics and Computation, vol. 215, no. 9, pp. 3449-3454, 2010.

[6] X. Wang and L. Liu, "Modified Ostrowski's method with eighth-order convergence and high efficiency index," Applied Mathematics Letters, vol. 23, no. 5, pp. 549-554, 2010.

[7] F. Soleymani, "On a new class of optimal eighth-order derivative-free methods," Acta Universitatis Sapientiae. Mathematica, vol. 3, no. 2, pp. 169-180, 2011.

[8] F. Soleymani, "Efficient optimal eighth-order derivative-free methods for nonlinear equations," Japan Journal of Industrial and Applied Mathematics, vol. 30, no. 2, pp. 287-306, 2013.

[9] F. Soleimani, F. Soleymani, and S. Shateyi, "Some iterative methods free from derivatives and their basins of attraction," Discrete Dynamics in Nature and Society, vol. 2013, Article ID 301718, 11 pages, 2013.

[10] F. Soleymani, "A new method for solving ill-conditioned linear systems," Opuscula Mathematica, vol. 33, no. 2, pp. 337-344, 2013.

[11] F. Soleymani, "A rapid numerical algorithm to compute matrix inversion," International Journal of Mathematics and Mathematical Sciences, vol. 2012, Article ID 134653, 11 pages, 2012.

[12] F. Soleymani, "On a fast iterative method for approximate inverse of matrices," Communications of the Korean Mathematical Society, vol. 28, pp. 407-418, 2013.

[13] D. K. R. Babajee and R. Thukral, "On a 4-point sixteenth-order King family of iterative methods for solving nonlinear equations," International Journal of Mathematics and Mathematical Sciences, vol. 2012, Article ID 979245, 13 pages, 2012.

[14] Y. H. Geum and Y. I. Kim, "A family of optimal sixteenthorder multipoint methods with a linear fraction plus a trivariate polynomial as the fourth-step weighting function," Computers \& Mathematics with Applications, vol. 61, no. 11, pp. 3278-3287, 2011.

[15] Y. H. Geum and Y. I. Kim, "A biparametric family of optimally convergent sixteenth-order multipoint methods with their fourth-step weighting function as a sum of a rational and a generic two-variable function," Journal of Computational and Applied Mathematics, vol. 235, no. 10, pp. 3178-3188, 2011.

[16] C. Chun, "Construction of Newton-like iteration methods for solving nonlinear equations," Numerische Mathematik, vol. 104, no. 3, pp. 297-315, 2006. 


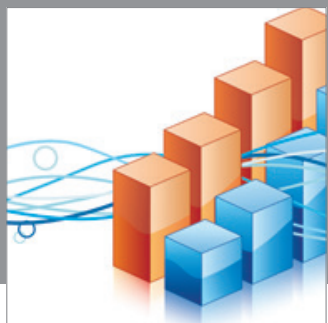

Advances in

Operations Research

mansans

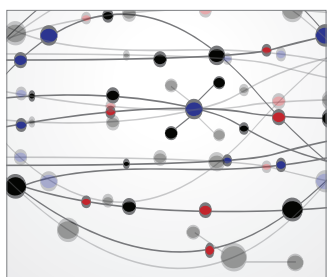

The Scientific World Journal
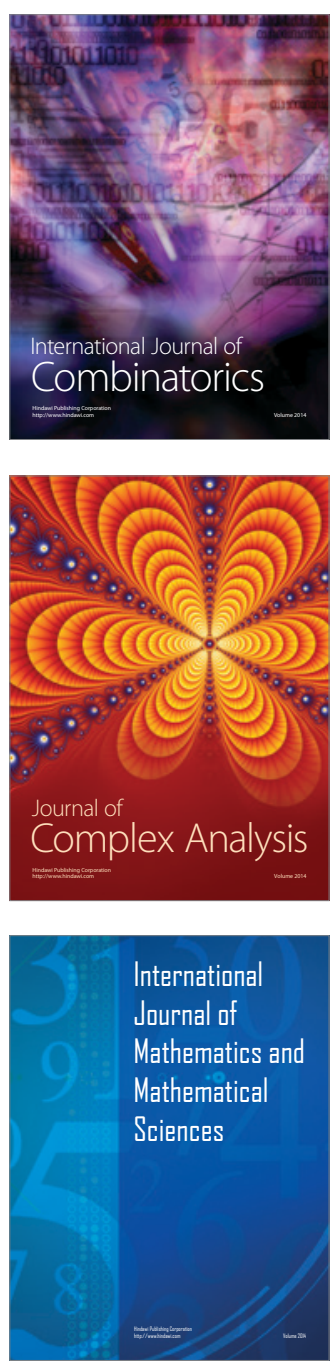
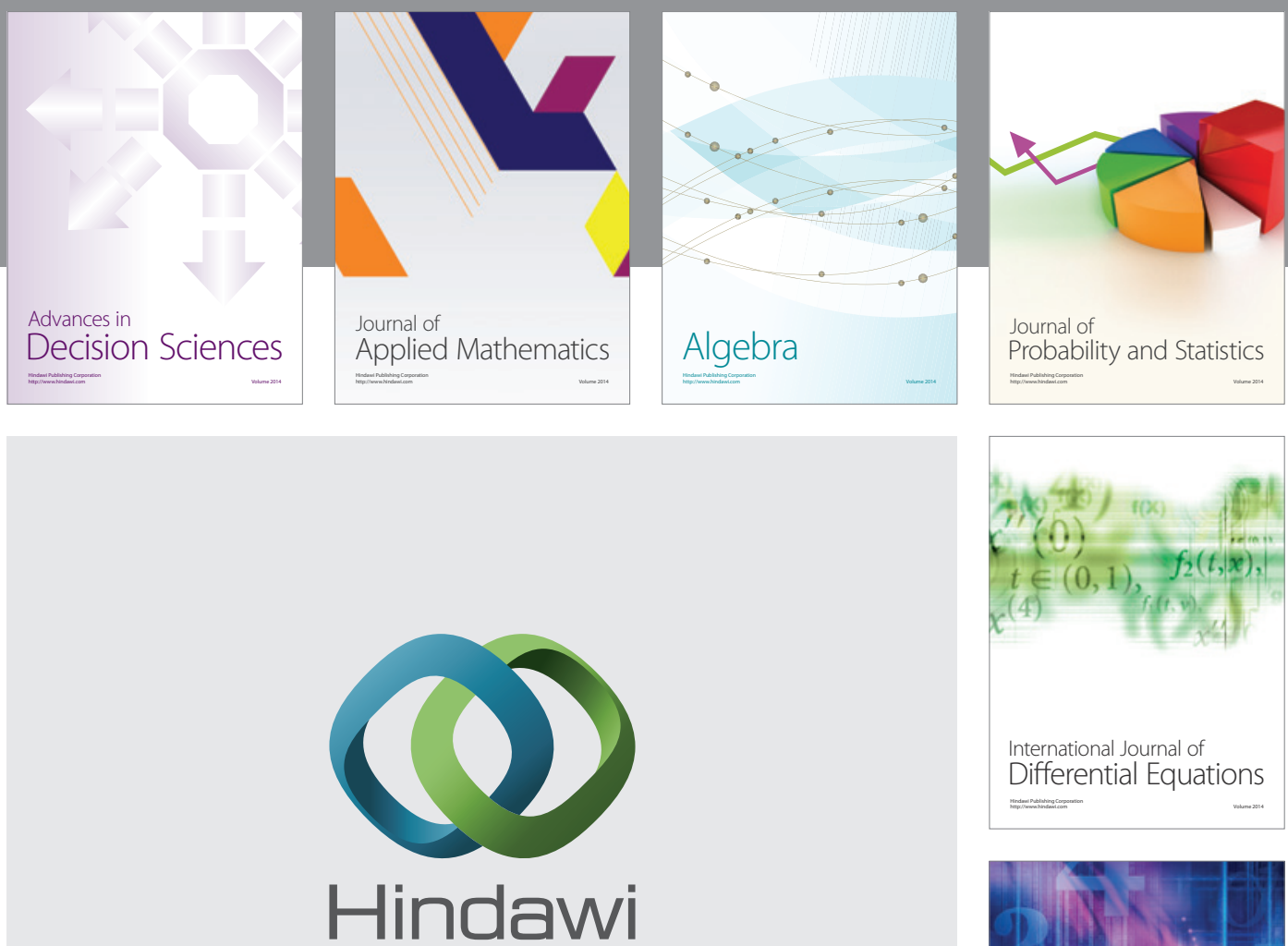

Submit your manuscripts at http://www.hindawi.com
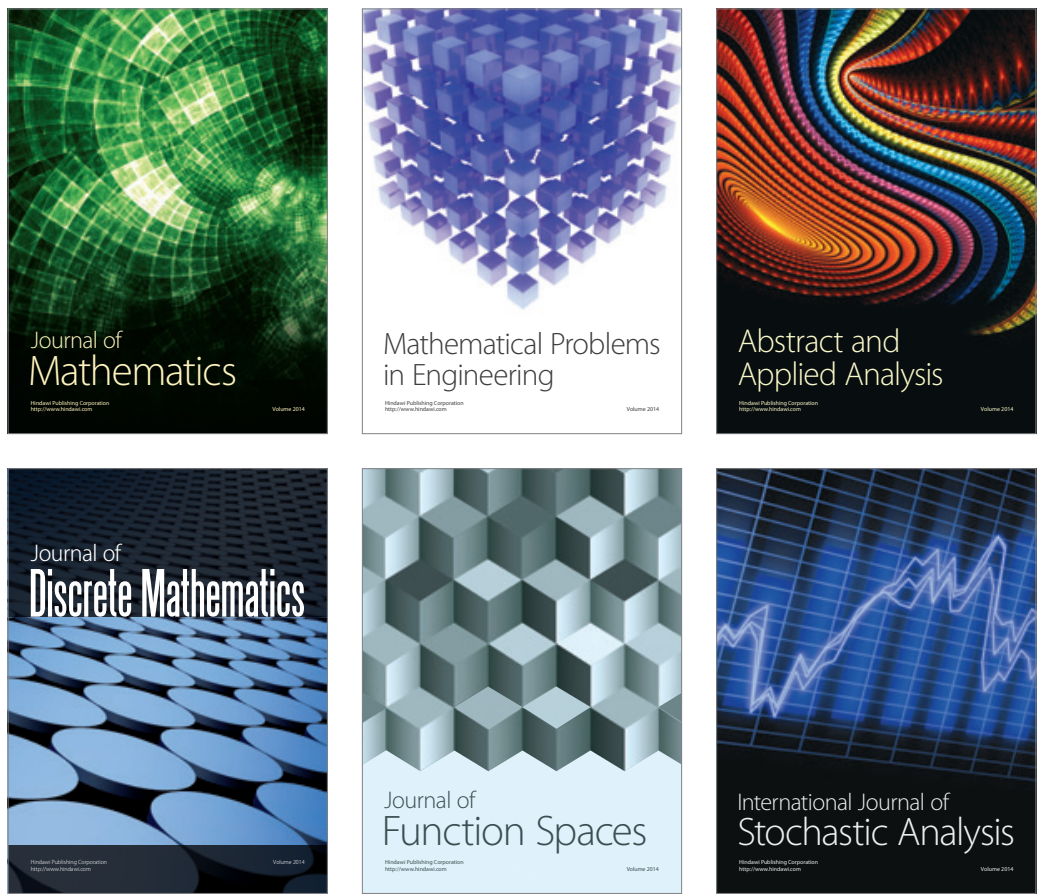

Journal of

Function Spaces

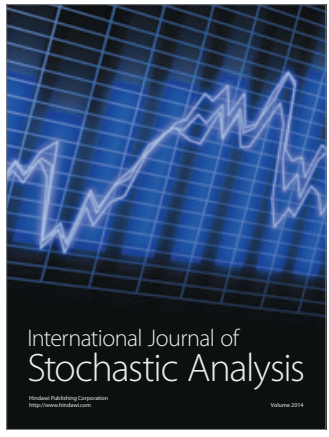

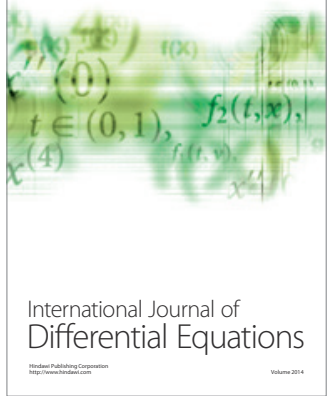
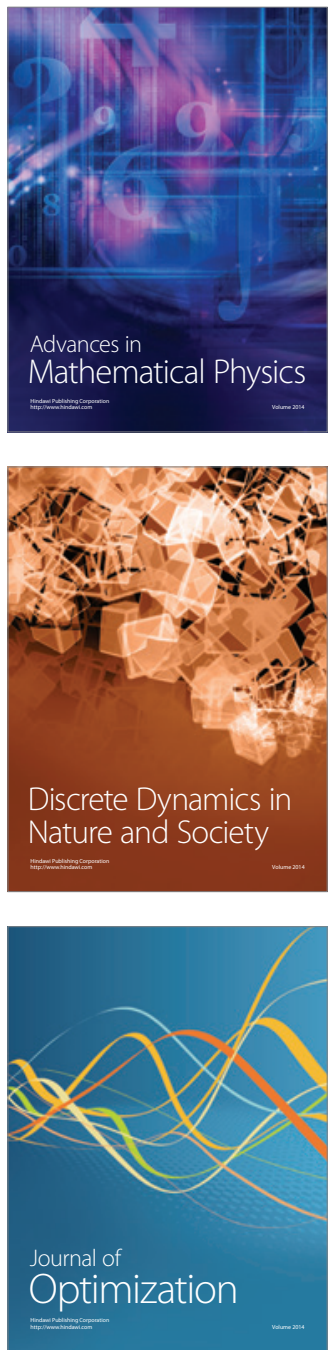